\title{
The diagnostic value of alcohol dehydrogenase (ADH) isoenzymes and aldehyde dehydrogenase (ALDH) measurement in the sera of patients with brain tumor
}

Wojciech Jelski ${ }^{1}$, Magdalena Laniewska-Dunaj ${ }^{1}$, Karolina Orywal ${ }^{1}$, Jan Kochanowicz ${ }^{2}$, Robert Rutkowski², Maciej Szmitkowski ${ }^{1}$

${ }^{1}$ Department of Biochemical Diagnostics, Medical University, Bialystok, Poland ${ }^{2}$ Department of Neurosurgery, Medical University, Bialystok, Poland

Submitted: 30 January 2015

Accepted: 10 April 2015

Arch Med Sci 2017; 13, 2: 346-352

DOI: https://doi.org/10.5114/aoms.2017.65366

Copyright (c) 2017 Termedia \& Banach

\section{Abstract}

Introduction: Alcohol dehydrogenase (ADH) isoenzymes and aldehyde dehydrogenase (ALDH) exist in the brain. Alcohol dehydrogenase and ALDH are also present in brain tumor cells. Moreover, the activity of class I isoenzymes was significantly higher in cancer than healthy brain cells. The activity of these enzymes in tumor tissue is reflected in the serum and could thus be helpful for diagnostics of brain neoplasms. The aim of this study was to investigate the potential role of $A D H$ and ALDH as markers for brain tumors. Material and methods: Serum samples were taken for routine biochemical investigation from 115 patients suffering from brain tumors (65 glioblastomas, 50 meningiomas). For the measurement of the activity of class I and II ADH isoenzymes and ALDH activity, fluorometric methods were used. The total ADH activity and activity of class III and IV isoenzymes were measured by the photometric method.

Results: There was a significant increase in the activity of ADH I isoenzyme and $\mathrm{ADH}$ total in the sera of brain tumor patients compared to the controls. The diagnostic sensitivity for ADH I was $78 \%$, specificity $85 \%$, and positive and negative predictive values were $86 \%$ and $76 \%$ respectively. The sensitivity and specificity of ADH I increased with the stage of the carcinoma. Area under receiver-operating characteristic curve for ADH I was 0.71.

Conclusions: The results suggest a potential role for $\mathrm{ADH}$ I as a marker for brain tumor.

Key words: alcohol dehydrogenase isoenzymes, aldehyde dehydrogenase, brain tumor.

\section{Introduction}

Neoplasms of the central nervous system (CNS) are a diverse group of tumors with different types of primary brain tumors and metastatic tumors. Glioblastoma and meningioma are the most common subtypes, accounting for over $80 \%$ of brain tumor cases [1]. Brain cancer, one of the top 10 causes of cancer deaths, remains a serious health threat and is largely incurable. Tumors of the CNS are typically diagnosed after symptoms including headache, nausea, personality changes or focal neurologic impairments appear. The early and accurate diagnosis of a brain tumor is essential for disease management. Therefore it is very important to

\author{
Corresponding author: \\ Wojciech Jelski MD \\ Department of \\ Biochemical Diagnostics \\ Medical University \\ 15 A Waszyngtona St \\ 15-269 Bialystok, Poland \\ Phone: +48 857468587 \\ Fax: +48 857468585 \\ E-mail:wjelski@umb.edu.pl
}


find markers to detect a malignant cell transformation as early as possible. There are no blood biomarkers useful in the diagnosis of patients with the most common types of brain tumors [2]. Numerous studies have shown that alcohol dehydrogenase $(\mathrm{ADH})$ and aldehyde dehydrogenase $(\mathrm{ALDH})$ are present in the cells of human brain tissues $[3,4]$. These enzymes are responsible for metabolism of many biological substances such as ethanol, retinol, and serotonin [5]. In our previous study we found that cancer tissue expresses ADH isoenzymes and ALDH activities. Moreover, the activity of total alcohol dehydrogenase and class I isoenzymes was significantly higher in neoplasm cells than in healthy tissue [6]. The changed activities of these enzymes in brain tissue are reflected in the sera. The total ADH activity was found to be elevated in the serum of patients with brain tumor. The increase of total ADH activity correlated with class I ADH and seems to be caused by the release of this isoenzyme from cancer cells [7].

In the current study, which is continuation of our previous investigations, we defined the diagnostic criteria such as diagnostic sensitivity, specificity, predictive value for positive (PVPR) and negative (PVNR) results, and receiver-operating characteristic (ROC) curves of tested enzymes. These data may be used in the evaluation of ADH and ALDH as candidates for tumor markers in brain cancer patients.

\section{Material and methods}

\section{Patients}

The protocol was approved by the Human Care Committee of the Medical University in Bialystok, Poland (Approval No. R-I-002/460/2011). All patients gave informed consent for the examination.

Serum samples were taken for routine biochemical investigations from 115 patients suffering from brain tumors (62 males and 53 females, range: 2879 years). All tumor patients were identified from January 2011 to June 2014 in Department of Neurosurgery, Medical University of Bialystok (Poland). Among the cancer patients, 65 patients (41 men and 24 women) were suffering from glioblastoma and 50 patients ( 27 men, 23 women) had meningioma. The tumors were histopathologically classified according to World Health Organization criteria. We created the following groups, depending on the location of the tumor: frontal lobe, temporal lobe, parietal lobe, cerebellum. Classification was based on preoperative computed tomography (CT) and magnetic resonance imaging scans. Preoperative functional status of the patient was evaluated with the Karnofsky Performance Status Scale. Preoperative magnetic resonance imaging (MRI) was used to determine tumor volumes. None of the pa- tients had received chemotherapy or radiotherapy before sample collection. All of the patients drank alcohol occasionally and self-reported an intake of $<25 \mathrm{~g}$ of ethanol per week. The clinicopathological characteristics of the patients are shown in Table I.

Serum samples were also obtained from 150 healthy subjects (control group, 80 males, $60 \mathrm{fe-}$ males, aged 30-75 years). Control subjects were selected from healthy community residents who attended the hospitals for routine physical checkups at the Department of Preventive Medicine. All were volunteers and were defined as those with normal results of all physical, blood examinations and $\mathrm{CT}$ of the brain. Before the examinations con-

Table I. Characteristics of brain cancer patients

\begin{tabular}{|c|c|}
\hline Variable & No. of patients \\
\hline Brain cancer patients & 115 \\
\hline \multicolumn{2}{|l|}{ Gender: } \\
\hline Males & 62 \\
\hline Females & 53 \\
\hline \multicolumn{2}{|l|}{ Age } \\
\hline$<50$ years & 62 \\
\hline$\geq 50$ years & 53 \\
\hline Range & $28-78$ \\
\hline \multicolumn{2}{|l|}{ Histological type: } \\
\hline Glioblastoma & 65 \\
\hline Meningioma & 50 \\
\hline \multicolumn{2}{|l|}{ Tumor stage: } \\
\hline I & 30 \\
\hline ॥ & 26 \\
\hline III & 27 \\
\hline IV & 32 \\
\hline \multicolumn{2}{|l|}{ Tumor size $[\mathrm{cm}]$ : } \\
\hline$<3$ & 60 \\
\hline$\geq 3$ & 55 \\
\hline \multicolumn{2}{|l|}{ Location in the brain: } \\
\hline Frontal lobe & 30 \\
\hline Temporal lobe & 35 \\
\hline Parietal lobe & 28 \\
\hline Cerebellum & 22 \\
\hline \multicolumn{2}{|c|}{ Degree of differentiation: } \\
\hline Good & 68 \\
\hline Poor & 47 \\
\hline
\end{tabular}


trol subjects had not consumed alcohol for almost one month and ethanol did not exist in serum samples of any subject when it was collected.

\section{Biochemical assays}

\section{Determination of total ADH activity}

Total ADH activity was estimated by the photometric method with $p$-nitrosodimethylaniline (NDMA) as a substrate [8]. The reaction mixture $(2 \mathrm{ml})$ contained $0.1 \mathrm{ml}$ of serum and $1.8 \mathrm{ml}$ of a $26 \mu \mathrm{M}$ solution of substrate in $0.1 \mathrm{M}$ sodium phosphate buffer, $\mathrm{pH} 8.5$ and $0.1 \mathrm{ml}$ of a mixture containing $0.25 \mathrm{M} \mathrm{n}$-butanol and $5 \mathrm{mM}$ NAD. The reduction of NDMA was monitored at $440 \mathrm{~nm}$ on a Shimadzu UV/VIS 1202 spectrophotometer (Shimadzu Europa GmbH, Duisburg, Germany).

\section{Determination of total ALDH activity}

The ALDH activity was measured using the fluorogenic method based on the oxidation of 6-methoxy-2-naphthaldehyde to the fluorescent 6-methoxy-2 naphthoate [9]. The reaction mixture contained $60 \mu \mathrm{l}$ of serum, $60 \mu \mathrm{l}$ of substrate, $20 \mu \mathrm{l}$ of $11.4 \mathrm{mM} \mathrm{NAD}$ and $2.8 \mathrm{ml}$ of $50 \mathrm{mM}$ of sodium phosphate buffer, $\mathrm{pH}$ 8.5. The mixture also contained $50 \mu \mathrm{l}$ of a $12 \mathrm{mM}$ solution of 4-methylpyrazole as a specific inhibitor of ADH activity. The fluorescence was read at excitation wavelength $310 \mathrm{~nm}$ and emission wavelength $360 \mathrm{~nm}$.

\section{Determination of class I and II ADH isoenzymes}

Class I and II alcohol dehydrogenase isoenzyme activity was measured using fluorogenic substrates (4-methoxy-1-naphthaldehyde for class I and 6-methoxy-2-naphthaldehyde for class II) in the reduction reaction according to Wierzchowski et al. [10]. The assays were performed in a reaction mixture containing a serum $(60 \mu \mathrm{l})$, substrate $(150 \mu \mathrm{l}$ of $300 \mu \mathrm{M})$, $\mathrm{NADH}(100 \mu \mathrm{l}$ of $1 \mathrm{mM})$ and $0.1 \mathrm{M}$ sodium phosphate buffer, $\mathrm{pH} 7.6(2.69 \mathrm{ml})$, in conditions previously described [11]. The measurements were performed on a Shimadzu RF-5301 spectrofluorophotometer (Shimadzu Europa GmbH, Duisburg, Germany) at excitation wavelength $316 \mathrm{~nm}$ for both substrates and emission wavelength of $370 \mathrm{~nm}$ for class I and $360 \mathrm{~nm}$ for class II isoenzymes.

\section{Determination of class III ADH isoenzyme}

The assay mixture for class III alcohol dehydrogenase activity contained a serum $(100 \mu \mathrm{l})$, n-octanol as a substrate $(31 \mu \mathrm{l}$ of $1 \mathrm{mM}), \mathrm{NAD}(240 \mu \mathrm{l}$ of $1.2 \mathrm{mM}$ ) in $0.1 \mathrm{M} \mathrm{NaOH}$-glycine buffer, $\mathrm{pH} 9.6$ [12]. The reduction of NAD was monitored at $340 \mathrm{~nm}$ and $25^{\circ} \mathrm{C}$ on a Shimadzu UV/VIS 1202 spectrophotometer.

\section{Determination of class IV ADH isoenzyme}

The assay mixture for class IV alcohol dehydrogenase activity contained a serum $(50 \mu \mathrm{l})$, m-nitrobenzaldehyde as a substrate of $(132 \mu \mathrm{l}$ of $80 \mu \mathrm{M}), \mathrm{NADH}(172 \mu \mathrm{l}$ of $86 \mu \mathrm{M})$ in $0.1 \mathrm{M}$ sodium phosphate buffer, pH $7.5[13,14]$. The oxidation of $\mathrm{NADH}$ was monitored at $340 \mathrm{~nm}$ and $25^{\circ} \mathrm{C}$ on a Shimadzu UV/VIS 1202 spectrophotometer.

\section{Diagnostic values calculation}

The diagnostic criteria, such as diagnostic sensitivity, specificity, predictive and negative value and the ROC curve, were determined using the program GraphROC for Windows (University of Turku, Turku, Finland) [15].

$$
\begin{aligned}
& \text { Sensitivity }=\frac{\text { number of true-positive results }}{\begin{array}{l}
\text { number of true-positive results }+ \\
\text { number of false-negative results }
\end{array}} \times 100 \% \text {. } \\
& \text { Specificity }=\frac{\text { number of true-negative results }}{\text { number of true-negative results }+} \times 100 \% \text {. } \\
& \text { number of false-positive results }
\end{aligned}
$$

$\begin{aligned} & \text { Positive } \\ & \text { predictive }= \\ & \text { value }\end{aligned} \quad \begin{aligned} & \text { number of true-positive results } \\ & \text { number of true-positive results }+ \\ & \text { number of false-positive results }\end{aligned} \times 100 \%$.

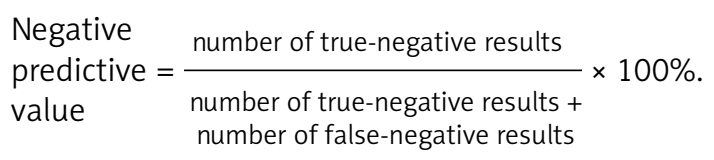

\section{Statistical analysis}

A preliminary statistical analysis ( $\chi^{2}$ test) revealed that the distribution of ADH and ALDH activities did not follow a normal distribution. Consequently, Wilcoxon's test was used for statistical analysis. Data were presented as median, range and mean values. Statistically significant differences were defined as comparisons resulting in $p<0.05$.

\section{Results}

The activities of alcohol dehydrogenase, aldehyde dehydrogenase and isoenzymes of alcohol dehydrogenase in the sera of patients with brain tumor are presented in Table II. The total alcohol dehydrogenase activity was significantly higher (about 28\%) in patients with brain tumor than in the healthy subjects. The analysis of ALDH activity did not show a significant difference between the total tested group and healthy subjects. The 
Table II. The ADH and ALDH activity in the sera of patients with brain cancer depending on the stage of carcinoma

\begin{tabular}{|lcccccc|}
\hline Variable & $\begin{array}{c}\text { ADH total } \\
\text { Median } \\
\text { Range }\end{array}$ & $\begin{array}{c}\text { ALDH total } \\
\text { Median } \\
\text { Range }\end{array}$ & $\begin{array}{c}\text { ADH I } \\
\text { Median } \\
\text { Range }\end{array}$ & $\begin{array}{c}\text { ADH II } \\
\text { Median } \\
\text { Range }\end{array}$ & $\begin{array}{c}\text { ADH III } \\
\text { Median } \\
\text { Range }\end{array}$ & $\begin{array}{c}\text { ADH IV } \\
\text { Median } \\
\text { Range }\end{array}$ \\
\hline $\begin{array}{l}\text { Total group } \\
(n=115)\end{array}$ & $942^{*}$ & 2.88 & $1.92^{*}$ & 15.06 & 12.58 & 5.55 \\
\hline Stage I & $314-1718$ & $1.22-5.95$ & $1.02-4.25$ & $6.67-22.16$ & $6.84-18.66$ & $2.02-12.68$ \\
$(n=30)$ & $911^{*}$ & 2.79 & $1.81^{*}$ & 14.55 & 12.18 & 5.39 \\
\hline Stage II & $314-1485$ & $1.22-5.51$ & $1.02-3.95$ & $6.67-18.90$ & $6.84-18.12$ & $2.02-12.31$ \\
$(n=26)$ & $937^{*}$ & 2.64 & $1.90^{*}$ & 14.92 & 12.44 & 5.48 \\
\hline Stage III & $423-1541$ & $1.46-5.72$ & $1.21-4.02$ & $6.91-19.22$ & $6.99-18.40$ & $2.26-12.49$ \\
$(n=27)$ & $973^{*}$ & 2.94 & $2.04^{*}$ & 15.24 & 12.52 & 5.62 \\
\hline Stage IV & $462-1699$ & $1.51-5.90$ & $1.48-4.07$ & $7.13-21.07$ & $7.11-18.45$ & $2.31-12.57$ \\
$(n=32)$ & $4698^{*}$ & 3.03 & $2.17^{*}$ & 15.33 & 12.78 & 5.77 \\
\hline Control & 682 & $1.62-5.95$ & $1.60-4.25$ & $7.20-22.16$ & $7.25-18.66$ & $2.60-12.68$ \\
$(n=150)$ & $299-1366$ & $1.06-5.49$ & $0.84-3.16$ & $5.67-20.05$ & $7.03-17.77$ & $1.88-11.85$ \\
\hline
\end{tabular}

Table III. Diagnostic criteria for ADH total and ADH I for brain cancer

\begin{tabular}{|lccccc|}
\hline Parameter & $\begin{array}{c}\text { Cut-off } \\
{[\mathrm{mU} / \mathrm{l}]}\end{array}$ & $\begin{array}{c}\text { Diagnostic } \\
\text { sensitivity (\%) }\end{array}$ & $\begin{array}{c}\text { Diagnostic } \\
\text { specificity (\%) }\end{array}$ & $\begin{array}{c}\text { Positive } \\
\text { predictive value (\%) }\end{array}$ & $\begin{array}{c}\text { Negative } \\
\text { predictive value (\%) }\end{array}$ \\
\hline ADH total & 1150 & 62 & 71 & 77 & 71 \\
\hline ADH I & 3.00 & 78 & 85 & 86 & 76 \\
\hline
\end{tabular}

The cut-off points were obtained from a study of a healthy population (97.5 percentile).

comparison of ADH isoenzymes' activities showed that the largest difference was exhibited by ADH I. The median activity of this class isoenzyme in the total brain tumor group increased by about $27 \%$ (1.92 $\mathrm{mU} / \mathrm{l})$ in comparison to the control level $(1.40 \mathrm{mU} / \mathrm{l})$. This increase was statistically significant $(p<0.05)$. The other tested classes of alcohol dehydrogenase isoenzymes had higher activities in the serum of patients with brain tumor, but the differences were not statistically significant in all patients groups $(p>0.05)$.

Having analyzed the activity of particular alcohol dehydrogenase isoenzymes depending on the progression stage of the carcinoma, the tendency of ADH I activity to increase in accordance with the progression of disease was observed. Significantly higher ADH class I activity was found in the cancer patients regardless of stage in comparison to the control group. The other isoenzymes did not exhibit marked changes of activity among patients at various stages of the tumor. The serum level of total ADH activity was significantly higher in the cancer patient group (each stage) compared with the control group. We also observed a tendency towards an increase of the total ADH activity together with the progression of the carcinoma. In contrast, the activity of aldehyde dehydrogenase did not show significant one-way changes.

Table III shows the diagnostic criteria for ADH total and ADH I. The sensitivity (78\%) and specificity (85\%) of ADH I were higher than values for $\mathrm{ADH}$ total. Both the positive predictive value and negative predictive value were also the highest for $\mathrm{ADH}$ I. Sensitivity of ADH I was higher in a more advanced tumor stage (Figure 1).

The relationship between diagnostic sensitivity and specificity was illustrated by a ROC curve (Figure 2). It shows that the ADH I area under the ROC curve (0.71) was higher than the ROC area of $\mathrm{ADH}$ total (0.66).

\section{Discussion}

Brain tumors are one of the most challenging disorders encountered, and early and accurate diagnosis is essential for the management and treatment of these tumors. The diagnosis of brain neoplasms is still confirmed with histopathology examination and must start with careful neuro-

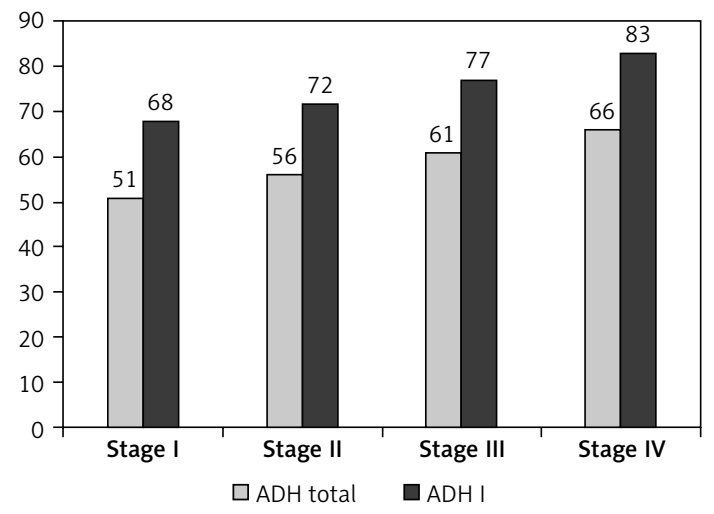

Figure 1. Diagnostic sensitivity of $A D H$ total and $\mathrm{ADH} I$ in brain cancer depending on the stage of carcinoma 


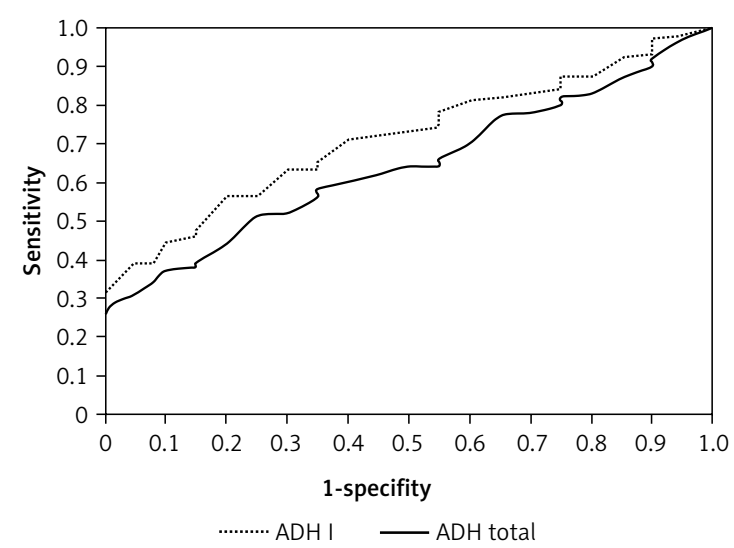

Figure 2. Areas under ROC curves for $A D H I$ and total ADH activity (ADH I, area $=0.7103, \mathrm{SE}=0.0552$, $\mathrm{ADH}$ total, area $=0.6614, \mathrm{SE}=0.0631)$

logic examination followed by appropriate central nervous system (CNS) imaging. At the moment, neuroimaging methods are characterized by a lack of specificity for differentiation of brain tumors. The tumor typing and grading are still determined by histopathological assessment of tissue sample and requirement surgical intervention [16]. Currently, there are no generally accepted screening protocols for the diagnosis of brain tumors [17]. For a long time attempts have been made to find markers for detection of malignant cell transformation as early as possible. Tumor markers are substances expressed in various biological fluids or tissues which could indicate the presence of a neoplasm. These substances should be synthesized and excreted by tumor tissues [18]. The best solution in the process of brain tumor diagnosis could be readily available biomarkers that should be useful in the monitoring of the disease course, differential diagnosis and planning surgical intervention [19]. In our previous study, we found that the activity of human alcohol dehydrogenase is significantly higher in brain carcinoma tissue than that in healthy tissue and the activity of aldehyde dehydrogenase is not different between both tissues [6]. Moreover, the data of the same study showed that only the activity of class I ADH is significantly higher in cancer than in unchanged cells. The other tested classes of isoenzymes had higher activities in cancer tissue than in healthy brain cells, but the differences were not statistically significant [6]. The increases of enzyme activity in the tumor are reflected by increase of their activity in the serum. We have found that the serum total alcohol dehydrogenase activity is changed in the course of CNS neoplasms. The increase of total $A D H$ was positively correlated with $A D H ~ I$, so the cause of the increase of serum total alcohol dehydrogenase activity in the course of brain tumor is an elevation of class I ADH isoenzyme. We also observed a tendency towards an increase of the total ADH activity together with the progression of the carcinoma. Histological grading of brain neoplasms might help in predicting their biological behavior [20]. Therefore, detailed analysis of alcohol dehydrogenase and aldehyde dehydrogenase activity in relation to WHO grade of CNS tumors was performed in the current study. According to the WHO classification, grade I and II apply to lesions with low proliferative potential, while grades III and IV are generally reserved for lesions with histological evidence of malignancy [20]. We revealed that serum ADH activity was higher in patients with a more advanced tumor grade according to the WHO classification when compared to patients with lower grades of tumors, but these differences were significant only in comparison to the healthy group. The present study is a continuation of our previous research. Higher levels of ADH in patients with more advanced tumors might result from enzyme release by cancer cells and could be helpful for diagnosing brain tumors. The diagnostic criteria for disease markers are sensitivity, specificity and area under the curve (AUC). The ideal marker should possess very high specificity, i.e. not detectable in healthy subjects, and very high sensitivity, i.e. be very early on or when only a few cancer cells are present. The criteria for $100 \%$ sensitivity and $100 \%$ specificity have not as yet been fulfilled by any of the known tumor markers. In our present study, diagnostic sensitivity was highest for $\mathrm{ADH}$ I (78\%) and $\mathrm{ADH}$ total (62\%). The predictive value for positive results indicates the probability with which a tumor exists in the case of positive test results. The negative predictive value for negative results predicts the probability when a tumor exists in the case of negative test results. In this investigation, $\mathrm{ADH}$ I has high predictive values for positive and negative results ( $86 \%$ and $76 \%$ respectively). The most important criterion for tumor markers is the sensitivity/specificity diagram - the ROC curve. The area under the ROC curve indicates the clinical usefulness of tested substances. The larger area under the ROC curve corresponds to a better tumor marker. In this study the ADH I (0.71) area under the ROC curve was higher than for ADH total (0.66).

Our research shows that the activity of ADH I and ADH total in the blood of patients with a brain tumor after surgery and chemotherapy or radiotherapy significantly decreases. This effect is most seen after surgical resection of the tumor (unpublished data).

We analyzed the diagnostic parameters together for gliomas and meningiomas because in our previous studies, we found that ADH, ALDH and $\mathrm{ADH}$ isoenzyme activities in the serum did not indicate significant differences between patients 
with glioblastoma and meningioma [7]. This is surprising, because they differ in the degree of malignancy, the origin of the cells and etiology, but we found that the activity of ADH and ALDH in cancer tissues of glioblastoma did not differ from that of meningioma [6].

The research on cellular changes has shed invaluable light on the biochemistry and pathophysiology of brain tumors. Clinical use of molecular imaging methods is expanding and allows quantitative assessment [21]. In recent years, [18F]-fluoro-3'-deoxy3'-L: -fluorothymidine ([18F]FLT) has been developed as a proliferation tracer. Imaging and measurement of proliferation with positron emission tomography could provide us with a non-invasive staging tool and a tool to monitor the response to anticancer treatment [22]. The interesting key question remains whether the magnitude of biochemical alterations shown by molecular imaging reveals prognostic value with respect to survival, and whether it identifies early disease and differentiates benign from malignant lesions. In our opinion, changes in the activity of ADH may allow early detection and differentiation of benign from malignant.

The ADH and ALDH are cytoplasmic enzymes, but their effects can cause mitochondrial dysfunction. Differences of activity of various ADH isoenzymes between cancer cells and healthy tissue might be a factor of some disorders in metabolic pathways with participation of these isoenzymes, which can lead to carcinogenesis and may affect Warburg's effect.

Currently, only the measurement of beta subunit of human chorionic gonadotropin or $\alpha$-fetoprotein concentrations in the diagnosis of rare germ cell tumors and pituitary gland tumor is considered useful in routine clinical management [2]. However, these markers are typical only for specific and rare types of brain tumors. Novel research has assessed the blood concentrations of placental growth factor (PIGF), neuropeptide $Y$ (NPY), glial fibrillary acidic protein (GFAP) and brain-derived neurotrophic factor (BDNF) in patients with different types of CNS neoplasms [23, 24]. The authors of these investigations concluded that all biomarker concentrations were correlated with patient parameters, including neuropathological diagnosis. Some authors have suggested the role of selected matrix metalloproteinases (MMPs) and their tissue inhibitors (TIMPs) in the growth and progression of brain tumors $[25,26]$.

This is the first study showing all the diagnostic criteria for alcohol dehydrogenase and aldehyde dehydrogenase in brain tumor patients. The results obtained demonstrate the potential clinical role for $A D H$ (especially $A D H ~ I)$ as markers for brain cancer, but further investigations and confirmation by a prospective study are necessary.

\section{Conflict of interest}

The authors declare no conflict of interest.

\section{References}

1. Galeone C, Malerba S, Rota M, et al. A meta-analysis of alcohol consumption and risk of brain tumours. Ann Oncol 2012; 24: 514-23.

2. Jorsal T, Rørth M. Intracranial germ cell tumours. A review with special reference to endocrine manifestations. Acta Oncol 2012; 51: 3-9.

3. Galter D, Carmine A, Buervenich S, Duester G, Olson L. Distribution of class I, III and IV alcohol dehydrogenase mRNAs in the adult rat, mouse and human brain. Eur J Biochem 2003; 270: 1316-26.

4. Zimatkin SM, Pronko SP, Vasiliou V, Gonzalez FJ, Deitrich RA. Enzymatic mechanisms of ethanol oxidation in the brain. Alcohol Clin Exp Res 2006; 30: 1500-5.

5. Martinez SE, Vaglenova J, Sabria J, Martinez MC, Farres J, Pares X. Distribution of alcohol dehydrogenase mRNA in the rat central nervous system: consequences for brain ethanol and retinoid metabolism. Eur J Biochem 2001; 268: 5045-56

6. Łaniewska-Dunaj M, Jelski W, Orywal K, Kochanowicz J, Rutkowski R, Szmitkowski M. The activity of class I, II, III and IV of alcohol dehydrogenase (ADH) isoenzymes and aldehyde dehydrogenase (ALDH) in brain cancer. Neurochem Res 2013; 38: 1517-21.

7. Jelski W, Łaniewska-Dunaj M, Orywal K, Kochanowicz J, Rutkowski R, Szmitkowski M. The activity of alcohol dehydrogenase $(\mathrm{ADH})$ isoenzymes and aldehyde dehydrogenase $(A L D H)$ in the sera of patients with brain cancer. Neurochem Res 2014; 39: 2313-8.

8. Skursky L, Kovar J, Stachova M. A sensitive assay for alcohol dehydrogenase activity in blood serum. Anal Biochem 1979; 89: 65-71.

9. Chrostek L, Jelski W, Szmitkowski M, Puchalski W. Alcohol dehydrogenase (ADH) isoenzymes and aldehyde dehydrogenase (ALDH) activity in the human pancreas. Dig Dis Sci 2003; 48: 1230-3.

10. Wierzchowski J, Dafeldecker WP, Holmquist B, Vallee BL. Fluorimetric assay for isozymes of human alcohol dehydrogenase. Anal Biochem 1989; 178: 57-62.

11. Jelski W, Kozlowski M, Laudanski J, Niklinski J, Szmitkowski M. The activity of class I, II, III and IV alcohol dehydrogenase $(A D H)$ isoenzymes and aldehyde dehydrogenase $(A L D H)$ in esophageal cancer. Dig Dis Sci 2009; 54: 725-30.

12. Koivusalo M, Baumann M, Uotila L. Evidence for the identity of glutathione-dependent formaldehyde dehydrogenase and class III alcohol dehydrogenase. FEBS Lett 1989; 257: 105-9.

13. Dohmen K, Baraona E, Ishibashi H, et al. Ethnic differences in gastric sigma-alcohol dehydrogenase activity and ethanol first pass metabolism. Alcohol Clin Exp Res 1996; 20: 1569-76.

14. Jelski W, Łaniewska-Dunaj M, Strumnik A, Szmitkowki M. The alcohol dehydrogenase isoenzyme alcohol dehydrogenase IV as a candidate marker of Helicobacter pylori infection. Arch Med Sci 2014; 10: 951-5.

15. Kairisto V, Virtanen A, Uusipaikka E, et al. Method for determining reference changes from patients' serial data: example of cardiac enzymes. Clin Chem 1993; 39: 2298-304.

16. van den Bent MJ, Vogelbaum MA, Wen PY, Macdonald DR, Chang SM. End point assessment in gliomas: 
novel treatments limit usefulness of classical Macdonald's Criteria. J Clin Oncol 2009; 27: 2905-8.

17. Smith ER, Zurakowski D, Saad A, Scott RM, Moses MA. Urinary biomarkers predict brain tumor presence and response to therapy. Clin Cancer Res 2008; 14: 2378-86.

18. Lindblom A, Liljegren A. Tumour markers in malignancies. BMJ 2000; 320: 424-7.

19. Iwamoto FM, Hottinger AF, Karimi S, et al. Longitudinal prospective study of matrix metalloproteinase- 9 as a serum marker in gliomas. J Neurooncol 2011; 105: 607-12.

20. Louis DN, Ohgaki H, Wiestler OD, et al. The 2007 WHO classification of tumours of the central nervous system. Acta Neuropathol 2007; 114: 97-109.

21. Schaller BJ, Modo M, Buchfelder M. Molecular imaging of brain tumors: a bridge between clinical and molecular medicine? Mol Imaging Biol 2007; 9: 60-71.

22. Schaller BJ, Cornelius JF, Sandu N, Buchfelder M. Molecular imaging of brain tumors personal experience and review of the literature. Curr Mol Med 2008; 8: 711-26.

23. Ilhan-Mutlu A, Wagner L, Widhalm G, et al. Exploratory investigation of eight circulating plasma markers in brain tumor patients. Neurosurg Rev 2013; 36: 45-55.

24. Lukaszewicz-Zajac M, Mroczko B, Kornhuber J, Lewczuk P. Matrix metalloproteinases (MMPs) and their tissue inhibitors (TIMPs) in the tumors of central nervous system (CNS). J Neural Transm 2014; 12: 469-77.

25. Lin Y, Wang JF, Gao GZ, Zhang GZ, Wang FL, Wang YJ. Plasma levels of tissue inhibitor of matrix metalloproteinase-1 correlate with diagnosis and prognosis of glioma patients. Chin Med J 2013; 126: 4295-300.

26. Hormigo A, Gu B, Karimi S, et al. YKL-40 and matrix metalloproteinase-9 as potential serum biomarkers for patients with high-grade gliomas. Clin Cancer Res 2006; 12: $5698-704$ 